\title{
Internet-Based Fuzzy Multicriteria Decision Support System for Planning Integrated Solid Waste Management
}

\author{
Y. Zeng ${ }^{1 *}$ and K. M. Trauth ${ }^{2}$ \\ ${ }^{1}$ Office of Social and Economic Data Analysis, University of Missouri-Columbia, Columbia, MO 65211, USA \\ ${ }^{2}$ Department of Civil \& Environmental Engineering, University of Missouri-Columbia, Columbia, MO 65211, USA
}

\begin{abstract}
Solid waste management planning involves selecting a best combination of solid waste management options. The decision involves the perceptions and preferences of different groups of people and multiple, sometimes conflicting, project objectives that are expressed in subjective terms. As reported in this paper, these issues were addressed by developing a fuzzy multicriteria decision support system. An internet-based user-interactive decision-support application was developed based on fuzzy logic. Community specific data are stored in a centralized database and are accessible to others through a web browser. The decision support system is a tool for decision makers and environmental professionals to use in conducting local and regional integrated solid waste management planning. A case study was conducted to illustrate the application of the models. The case study evaluated eight alternatives for managing the waste stream entering the City of Columbia Sanitary Landfill and utilized waste characterization data, other solid waste related data from the City of Columbia and the open literature, as well as preferences assigned by the researchers. The results showed that an assigned Alternative 4, which is a combination of Material Recovery Facility (MRF) and Refuse-Derived Fuel Facility (RDF) could be distinguished as the alternative that best met the established criteria. The sensitivity analysis showed that the fuzzy ranking results were not sufficiently sensitive to the different aggregation operators for combining the fuzzy importance factors. The comparison of different composition operators showed that the sum-product composition operator allows greater differentiation in the solid waste management context.
\end{abstract}

Keywords: Fuzzy set theory, internet-based system, multicriteria decision support system, solid waste management planning

\section{Introduction}

To address the problem of the increasing amount of waste to be disposed of and limited landfill volumes, clearly the first option is to reduce the amount of waste generated. Such an approach is recommended by the U.S. Environmental Protection Agency (USEPA, 2005). However, even if programs to reduce waste generation are successful, some waste will still be produced. Therefore, the next approach is to manage the waste that is generated in a sustainable way so that it doesn't produce adverse environmental, social or economic effects. It is the intent of this paper to focus on developing models to assist in the management of that generated waste. The issues related to implementing solid waste source reduction and reuse programs were not investigated for this project. Project details are provided by Zeng (2004).

Environmental, social and economic considerations are the criteria upon which sustainability is evaluated. Due to the complexities involved in solid waste management, a single waste management option is not sufficient to meet the needs of every community while meeting regulatory requirements. The selection of the optimal combination of management options is critical to the performance and sustainability of the

\footnotetext{
* Corresponding author: zengyh@umsystem.edu
}

system. If the combination of management options is not optimal and thus creates a situation that does not respond to all three criteria, then the sustainability of the system is undermined.

Mathematical models have been developed to assist in planning a best system. Most of the models for solid waste management are economic optimization models (Kaila, 1987; Lund, 1990; Pugh, 1993; Lund et al., 1994; Anex et al., 1996; Chang et al., 1996; Everett and Shahi, 1996; Chang and Lin, 1997; Haith, 1998). However, the characteristics of real world decision-making for a sustainable solid waste management system are associated with multiple objectives including economic, environmental, and social ones. Some optimization models in the literature are conceptually difficult to formulate and hence difficult to adapt to a user's local setting.

Prior to this research, no comprehensive decision support tool was available to help decision makers handle the fuzziness and uncertainties involved in the solid waste management decision process associated with environmental, social, and economic impacts. The fuzziness is reflected in the fact that it is difficult to quantify such factors as environment impact, market stability, and adequacy of technology. In this kind of decision-making process, common knowledge, or expertise, often plays an important role, and thus, information may be expressed in linguistic terms or qualitative data such 
as good, fair, poor, etc. An example of imprecision is that it is difficult to obtain the precise cost of a waste management alternative (e.g., the cost of a materials recovery facility), in that the cost may vary with different designs, local conditions, types of materials recovered, etc. Consider a decision-making problem with the objective of "keeping the economic cost relatively low, minimizing environment impact, and maximizing public acceptance." Decisions still need to be made, even in the face of fuzziness and imprecision. Furthermore, there are often differences of opinion among stakeholders (including residents, politicians, technical professionals, etc.) on the importance of environmental, economic, and social factors. These issues are often community specific. The best plan for one community may not be the best for another community. As an example, some communities may support energy recovery, some may prefer greater jobs creation, while some communities may push for greater reductions in environmental discharges. The fuzzy approach developed in this paper can be very helpful in addressing all of these issues.

An internet-based decision support tool allows stakeholders to explore various management options and discover the individual environmental, economic, and social impacts of each. With this application, stakeholders can also record their preferences to be processed along with those of other interested parties. The combination of internet technology and advanced database systems make it possible to collect dynamic data interactively and generate dynamic research outputs and make the information available to the public. The national reference data is stored in the database, so decision makers can look them up during the process. The community can store historical data in the database and perform time series analyses and comparisons. As more and more people use the system, data from individual communities can be stored in the database and become available for others to utilize. The internet also allows for the process to occur during a time of public decision making in a format that is convenient for multiple users.

The objective of this research was to (1) develop an internet-based fuzzy decision support system for managing a solid waste stream, and (2) illustrate how to apply the method using a hypothetical case study. Data collected from Columbia, Missouri and from the open literature were used in the case study to illustrate the application of the internet-based fuzzy decision support system.

This problem can be described mathematically in the following fashion. Suppose a city would like to develop an integrated solid waste management plan. Let $P=\left\{p_{1}, p_{2}, p_{3}, \ldots\right.$, $\left.p_{n}\right\}$ be a set of integrated waste management options (decision alternatives) and $U=\left\{u_{1}, u_{2}, u_{3}, \ldots, u_{m}\right\}$ be a set of criteria according to which each alternative is evaluated. There will be several stakeholders such as politicians, the general public, environmental professionals, and non-profit environmental organizations. Their opinions should be taken into consideration during the decision making process. Let $\mathrm{S}=\left\{\mathrm{s}_{1}, \mathrm{~s}_{2}, \mathrm{~s}_{3}, \ldots\right.$, $\left.s_{k}\right\}$ be a set of stakeholders. The objective of the research, then, was to create a solid waste management methodology and tool that will determine the optimal alternative that will satisfy all criteria of all of the stakeholders to the greatest extent possible.

\section{Fuzzy Set}

The definition of a fuzzy set is discussed in multiple references, including, Zimmermann (1996), Wang (1997), Klir and Yuan (1995), Klir and Yuan (1996), Lowen (1996), and Fodor and Roubens (1994).

\subsection{Definition of Fuzzy Set and Aggregation Operator}

Given an arbitrary set $Z$, a fuzzy subset $\tilde{A}$ of $Z$ is defined by a membership function of its members:

$\mu_{\tilde{A}}: Z \rightarrow[0,1]$.

The value of $\mu_{\tilde{A}}(z)$ represents the grade of membership of $z$ in $\tilde{A}$. The nearer the value of $\mu_{\tilde{A}}(z)$ to unity, the higher the grade of the membership of $\mathrm{z}$ in $\tilde{A}$. In the literature, the membership function $\mu_{\tilde{A}}(z)$ is sometimes used to denote the fuzzy set. If $Z$ is a finite set whose elements are $Z_{1}$, $z_{2}, \ldots, z_{n}$, i.e., $Z=\left\{z_{1}, z_{2}, \ldots, z_{n}\right\}$, then a fuzzy set $\tilde{A}$ on $Z$ is expressed as:

$\tilde{A}=\left\{\left(z_{1}, \mu_{\tilde{A}}\left(z_{1}\right)\right),\left(z_{2}, \mu_{\tilde{A}}\left(z_{2}\right)\right), \ldots,\left(z_{n}, \mu_{\tilde{A}}\left(z_{n}\right)\right)\right\}$.

The finite fuzzy set is also sometimes expressed in a tabular format or vector format.

Different stakeholders have different opinions on the importance of each criterion. The "important criteria" constitute a fuzzy set $(I)$ on the set of criteria $(U)$. The word "important" is fuzzy like the word "young" in "young people". The members in $I$ are a subset of $U$ or all members in $U$. Each member in $I$ has a membership value associated with it. In a crisp set, a criterion can be either important or not important (membership value of 1 or 0 ). In a fuzzy set, the importance of the criteria can be quantified by a membership function, where each criterion has a certain degree of importance.

The "good alternatives" is a fuzzy set $(A)$ on a set of alternatives $(P)$. The fuzzy set $A(P)$ is the final objective. The element with the greatest membership value would be the best alternative that satisfies all the criteria and satisfies all the stakeholders the best.

Aggregation operations on fuzzy sets are functions by which several fuzzy sets or relations (fuzzy relations will be defined later) are combined in a meaningful way to produce a single fuzzy set or relation.

The operations for crisp sets are generalized to apply to fuzzy sets. The most commonly performed operations on fuzzy sets are fuzzy intersections and fuzzy unions. Zimmermann (1996) stated that the min operator $(\wedge)$ is a $t$-norm and the max operator $(\vee)$ is an $s$-norm, corresponding to set intersection and union operators, respectively. They 
correspond to logical operators of "and" and "or", respectively.

The membership function of the aggregated fuzzy set $M\left(X_{1}, X_{2}, \ldots, X_{n}\right)$ by the min operator is:

$\mu_{M}={ }_{i}^{\wedge} \mu_{X_{i}}$, where $i=1,2, \ldots, n$

where $X_{1}, X_{2}, \ldots, X_{n}$ are the fuzzy sets that need to be combined.

The membership function of aggregated fuzzy set $M\left(X_{1}\right.$, $\left.X_{2}, \ldots, X_{n}\right)$ by the max operator is:

$\mu_{M}=\underset{i}{\vee} \mu_{X_{i}}$, where $i=1,2, \ldots, n$

The plain set-theoretic operations (logical AND or OR) may not model well in some real systems or may not provide meaningful physical explanations of real systems (Wang, 1997). In the context of this study, if one uses the min operator, then only the lowest stakeholder rating would be utilized while if one uses the max operator, only the highest stakeholder rating would be utilized. Another category of operators are called averaging operators, in which the operation of aggregation arises as a sort of combination of pure logical AND or OR, providing some compensation effect. The most straightforward averaging operator is the arithmetic mean. Another averaging operator is the "fuzzy and" operator and it is defined as

$\mu_{M}=\lambda \wedge_{i} \mu_{X_{i}}+\frac{(1-\lambda) \sum_{i} \mu_{X_{i}}}{n}$

where $i=1,2 \ldots, n$. The $\lambda$ is a weighting parameter whose values range from 0 to 1 depending on how conservative one wants to be, with 1 being the most conservative. For $\lambda=1$, the "fuzzy and" becomes the min operator. For $\lambda=0$, the "fuzzy and" becomes the arithmetic mean.

The "fuzzy or" operator is another one of the averaging operators in contrast with the "fuzzy and" operator and it is defined as:

$\mu_{M}=\lambda \underset{i}{\vee} \mu_{X_{i}}+\frac{(1-\lambda) \sum_{i} \mu_{X_{i}}}{n}$

where $i=1,2, \ldots, n$. The $\lambda$ is a weighting parameter whose values range from 0 to 1 . For $\lambda=1$, the "fuzzy or" becomes the max operator. For $\lambda=0$, the "fuzzy or" becomes the arithmetic mean. A value of $\lambda=0.5$ was assumed for this study. This is just an arbitrary assumption. The selection of the $\lambda$ value is open for future research.

Different stakeholders may have different opinions on the importance of each criterion. There are thus multiple "important criteria" fuzzy sets. The "fuzzy and" operator will be used in the case study to aggregate the "important criteria" fuzzy sets. The effect of using other operators will be compared.

\subsection{Fuzzy Relations}

Fuzzy set theory suggests a different approach than classical methods to model the relations between the elements of sets. While a classical relation represents just the presence or absence of interaction or association among elements of given sets, the fuzzy relation uses the values of a membership function to represent degrees of association. The definition of a fuzzy relation is discussed below and is based on the work of Lowen (1996).

If $X$ and $Y$ are fuzzy sets or crisp sets, a fuzzy subset $R$ of $X \times Y$ is called a fuzzy relation on $X \times Y$, i.e., $R=\left\{\left((x, y), \mu_{R}\right.\right.$ $(x, y)) \mid(x, y) \in X \times Y\}$.

The satisfaction of the criteria by waste management alternatives can be quantified by a fuzzy relation $(R)$ between a set of criteria $(U)$ and a set of alternatives $(P)$, where $R$ is a fuzzy relation that can be described as elements of $P$ that substantially satisfy elements of $U$. The word "substantially" indicates the fuzziness about the relation. This relation can be represented by $R(U, P)$. In a crisp relation, a criteria is either satisfied by the alternative or not (membership value of 1 or 0 ). In a fuzzy relation, the satisfaction of criteria can be quantified by a membership function, where a criterion can be satisfied to a certain degree.

The membership function for the fuzzy relation could take the form of a linear, exponential, hyperbolic, etc., equation depending on the nature of the relation. The membership function that quantifies the satisfaction relationship between alternatives and criteria can be defined as follows.

A decreasing linear membership function is described as:

$\mu_{R}(u, p)=\left\{\begin{array}{cc}1 & u(p) \leq u^{1} \\ \frac{u^{0}-u(p)}{u^{0}-u^{1}} & u^{1}<u(p)<u^{0} \\ 0 & u(p) \geq u^{0}\end{array}\right.$

where $u^{1}$ is the expected value of a criteria, $u^{0}$ is the allowable value of a criteria, and $u(p)$ is the criterion value for the alternative $p$.

In a practical case, the expected value and allowable value can be determined by expert opinion, USEPA standards, community needs, etc. There could be cases where stakeholders or expert groups have different opinions on expected and allowable values, which could result in the membership line approaching 0 or 1 more gradually. An increasing linear membership function could be described in a similar manner.

As discussed above, the membership function does not have to be linear, and could be described by various types of curves, such as the exponential. The exponential membership function can be expressed by the following equation:

$\mu_{R}(u, p)=a_{u}\left[1-\exp \left\{-\alpha_{u}\left(\frac{u(p)-u^{0}}{u^{1}-u^{0}}\right)\right\}\right]$ 
where $a_{u} \geq 1, \alpha_{u}>0$ or $a_{u}<0, \alpha_{u}<0$. When no data are available and time is limited, a linear membership function is the simplest form because only two data points are needed to determine the function. The exponential membership function would need 3 data points to be completely specified.

\subsection{Fuzzy Set-Relation Composition}

Fuzzy set-relation composition takes the same form as the fuzzy relation-relation composition. The composition of fuzzy set $V$ and fuzzy relation $E$ is denoted as $V o E$ and is defined as:

$$
O(o)=S_{v \in V}[V(v) \quad t \quad E(v, o)]
$$

where $O$ and $V$ are two fuzzy sets. $E(v, o)$ represents the fuzzy relation between $O$ and $V$.

The $t$ is any $t$-norm, and $s$ is any $s$-norm. Because the $t$-norm and $s$-norm can take on a variety of formulas, the most commonly used $t$-norms are min and product operator. The most commonly used s-norms are max and algebraic sum (Zimmermann, 1996). If fuzzy set theory is used for modeling real systems, not only is it important that the operators satisfy certain axioms such as associativity, and commutativity, but the operators must also be appropriate models for real system behavior. For solid waste management planning, it is more appropriate to use product and algebraic sum operators, because the min and max operators tend to eliminate information obtained in the solid waste decision process.

The composition of fuzzy set $V$ and fuzzy relation $E$ is further defined by its membership function:

$O(o)=\operatorname{sum}_{v \in V}[V(v) \cdot E(v, o)]$

where - represents the product operator and sum represents the algebraic sum operator.

The practical significance of fuzzy set-relation composition is that it is a transformation of a fuzzy set in one domain to a fuzzy set in another domain, where the two domains are associated through a fuzzy relation. According to the fuzzy set-relation composition rule, the composition of $I(U)$ and $R(U, P)$ will produce the fuzzy set $A(P)$. This is depicted in Figure 1.

\section{Internet-Based Methodology}

An internet-based tool that is accessible through commonly available web browsers has been created. The primary purpose of the tool is to develop an interactive online interface to a centralized database repository for solid waste management information and an accessible tool for solid waste management planning using the fuzzy methodology. It enables the interactive dynamic data collection and produces a dynamic output. The internet tool is based on a three-tier architecture: a client-side user interface, a set of server-side computational modules to implement the fuzzy methodology, and a relational database system. Figure 2 shows a screen shot of the manage project page, which displays the major functions of the decision support tool. Help buttons are available on various pages to provide walk-through steps for calculating criteria values and to provide typical literature values for references. The internet-based tool is an object-based software package, developed based on the .NET framework and C\# language. It is easy to maintain and extend. The database is implemented in MS Access. The software was written in a way so that it is easy to replace the MS Access database with an Oracle database or MS SQL database. This provides flexibility for future expansion.

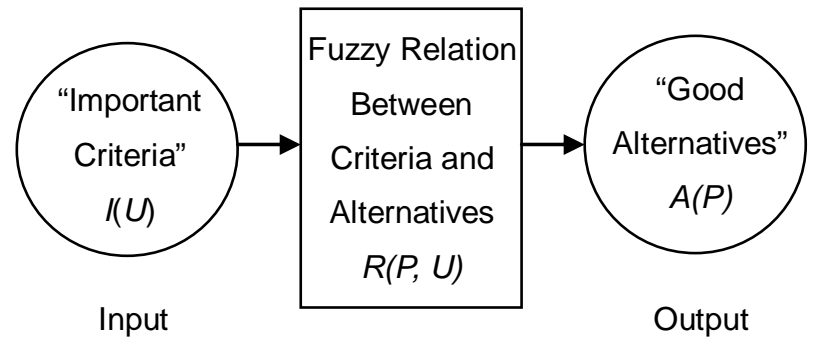

Figure 1. Fuzzy transformation between criteria and alternatives.

\section{Case Study}

The solid waste data used in this study were collected at the City of Columbia, Missouri Sanitary Landfill. This case study has been developed for the purpose of demonstrating how the fuzzy method is applied in a practical case with the help of the internet database application and to gain some understanding of different waste management options. Although efforts have been made to try to collect as much Columbia-specific data as possible, when Columbia data were not obtainable, literature values were used.

A total of 125,790 tons of waste (344.63 tons/day) (Table 1) entered the City of Columbia Sanitary Landfill during 1996 based on landfill scale house records. This waste came from primarily three counties (Audrain, Boone, and Callaway) and three cities (City of Centralia, City of Mexico, and City of Columbia). The City of Columbia contributes $55 \%$ of the total waste stream. A waste characterization study was performed on this waste stream in 1996 . The waste is $41.2 \%$ paper, $15.8 \%$ plastic, $6.1 \%$ metal, $2.9 \%$ glass, $21.2 \%$ organic, and $12.8 \%$ other wastes. The weights of the various waste components are listed in Table 1 . The detailed methods and results are reported in Zeng et al. (2005).

\subsection{Definition of Integrated Waste Management Alterna- tives}

A finite number of alternatives must be selected to serve 


\section{Fuzzy ISW Management System}

\section{Manage Project}

Please click on buttons to enter data for this project. Start with the first button and then work in cross-down order.

Project Name: Columbia Case Study

\begin{tabular}{|c|c|}
\hline Input System Info & Input Waste Composition \\
\hline Input Criteria & Input Stakeholders \\
\hline Input Importance Factors & Input Alternatives \\
\hline Input Criteria Values for Alternatives & Input Fuzzy Membership Function \\
\hline Execute Fuzzy Engine & Show Alternative Ranking \\
\hline
\end{tabular}

Home I Login I Choose Function Manage Project I Logout

Figure 2. Manage project page.

Table 1. Weight of Waste Component Categorized for Calculation of Inert Residue

\begin{tabular}{cccccc}
\hline Component & $\begin{array}{c}\text { Weight } \\
\text { (ton/yr) }\end{array}$ & $\begin{array}{c}\text { Weight after } \\
\text { recovery } \\
\text { (ton/yr) }\end{array}$ & $\begin{array}{c}\text { Percent of } \\
\text { Inert Residue } \\
(\%)\end{array}$ & $\begin{array}{c}\text { Residue } \\
\text { (ton/yr) }\end{array}$ & $\begin{array}{c}\text { Residue after } \\
\text { Recovery } \\
\text { (ton/yr) }\end{array}$ \\
\hline ORGANICS & & & & & \\
Food wastes & 10,632 & 10,632 & 5.0 & 531.6 & 531.6 \\
Paper ${ }^{(2)}$ & 24,952 & 4,990 & 6.0 & 1497.12 & 299.424 \\
Cardboard & 26,925 & 5,385 & 5.0 & 1346.25 & 269.25 \\
Plastics & 19,825 & 3,965 & 10.0 & 1982.5 & 396.50 \\
Textiles & 4,788 & 4,788 & 6.5 & 311.22 & 311.22 \\
Yard Waste & 1,650 & 1,650 & 4.5 & 74.25 & 74.25 \\
Wood & 8,898 & 8,898 & 1.5 & 133.47 & 133.47 \\
& & & & & \\
INORGANIC & & & & & \\
Glass & 3,612 & 722 & 98.0 & 3539.76 & 707.95 \\
Tin cans & 2,599 & 520 & 98.0 & 2547.02 & 509.40 \\
Aluminum & 1,079 & 216 & 96.0 & 1035.84 & 207.17 \\
Other metal & 3,908 & 782 & 98.0 & 3829.84 & 765.97 \\
Dirt, ash etc & 16,921 & 16,921 & 68.0 & 11506.28 & 11506.28 \\
Total (ton/day) & 344.63 & & & 77.63 & 43.05 \\
\hline
\end{tabular}

${ }^{(1)}$ Assume the recovery rate is $80 \%$.

${ }^{(2)}$ The bolded components are recyclable materials; the others are considered non-recyclable. 
as candidates for an integrated solid waste management plan for the community. Usually this involves organizing a taskforce to utilize local expertise that is familiar with and concerned about the details of waste management issues. Groups to solicit for taskforce membership include local elected officials, community/neighborhood groups, citizens, regulatory agencies, municipal employees (e.g., landfill operators, waste collection system representatives), and representatives from the recycling industry, the resource recovery industry and environmental groups. Part or all of these groups are the stakeholders referenced previously.

The next step is to assess the local waste stream through a waste characterization study and to assess the current status of waste management such as identifying problems, and setting objectives for the future (for example, meeting a specific diversion goal, solving a specific problem with the current system, or meeting specific community needs). The waste characterization study is reported in Zeng et al. (2005).

A set of solid waste plans $(P)$ can be then developed by analyzing the data accumulated in the previous steps. The set of alternatives $(P)$ developed for this study is defined as follows:

Alternative $1(p 1)$ : Collect and transport the mixed MSW to a landfill for disposal.

Alternative 2 ( $p 2)$ : Collect and transport the mixed MSW to a low-tech (low level of automation involved) material recovery facility (MRF) for on-site separation of recyclables; landfill the residue.

Alternative 3 (p3): Collect and transport the mixed MSW to a refuse derived fuel facility (RDF) for RDF preparation; remove the oversized material $(>500 \mathrm{~mm})$ at the beginning of the process; recover ferrous and non-ferrous metal and glasses; sell the glasses and ferrous metal to the recycling market; dispose of non-ferrous metal at the landfill; burn RDF fuel on-site in a incineration-boiler; landfill the residue.

Alternative $4(p 4)$ : Collect and transport the mixed MSW to a low-tech material recovery facility (MRF) for on-site separation of recycles; process the remaining waste in an RDF facility for RDF preparation with the product burned on site in a dedicated boiler; landfill the residue.

Alternative 5 (p5): Collect and transport the mixed MSW to a composting facility for preparation of compost; produce compost from the organic portion of the waste; landfill the non-organic portion of the waste.

Alternative 6 (p6): Collect and transport the mixed MSW to a low-tech material recovery facility (MRF) for on-site separation of recycles; compost the remainder of the waste in a composting facility for preparation of compost; landfill the residue.

Alternative 7 ( $p 7)$ : Collect and transport the mixed MSW to an incineration facility to recover energy from waste; monofill the ash.

Alternative $8(p 8)$ : Collect and transport the mixed MSW to a low-tech material recovery facility (MRF) for on-site separation of recycles; mass burn the remaining waste in a mass burn facility; monofill the ash.

The above alternatives $(P)$ developed for this study are depicted in Figure 3, where source reduction is considered to be an activity that takes place outside of the system boundary of the model. The Columbia collection system only collects waste from the City of Columbia. It does not collect waste from outside of Columbia. However, the waste from other counties also goes to the City of Columbia Landfill. Therefore, the collection system for the waste stream of other counties is considered outside of the system boundary. This situation is shown in Figure 3 for Alternative 1, but is omitted from other alternatives for simplicity. The collection element in Figure 3 is assumed for the Columbia waste stream only. The mass balance calculations are given as follows:

Alternative 1: The mass balance for Alternative 1 is straightforward. Direct data indicate that 344.63 tons per day (tpd) of waste (Table 1) were disposed of at the landfill directly.

Alternative 2: The recyclable materials in the Columbia Sanitary Landfill waste stream in 1996 are shown in Table 2. The total weight of recyclables is 43,199 tons/yr (118.35 tpd) (Table 2). It is assumed that the recovery rate is $80 \%$. This is a typical value taken from the literature. The recovered materials are then $118.35 \times 80 \%=94.68 \mathrm{tpd}$. The remaining waste is $344.63 \mathrm{tpd}-94.68 \mathrm{tpd}=249.95 \mathrm{tpd}$.

Alternative 3: The quality of the RDF fuel depends on the degree to which non-combustibles are removed. Usually an RDF facility uses equipment similar to that in an MRF facility to remove the non-combustibles. For this study, it is assumed that glass and metal are recovered and sold to the recycling market because they are basically non-combustible. The total weight of glass and metals is 11,198 tons (30.68 tpd) (Table 1). If one assumes an $80 \%$ recovery rate for glass and metal (non-ferrous and other glass were assumed not recoverable), the recovered material is 8,127 tons (22.27 tpd) (Table 1), with 8.41 tpd (including 1.63 tpd non-ferrous metal and 1.21 tpd other glass) going to the landfill. If one assumes that $10 \%$ of the corrugated board is oversized $(>500 \mathrm{~mm})$ and is removed and disposed of at the landfill ( $4.37 \mathrm{tpd})$, the total solid waste disposed of at the landfill is $12.78 \mathrm{tpd}(8.41+4.37$ tpd). Based on McDougall (2001), the ash produced from burning RDF plus the sludge of the wet-gas scrubbing gas cleaning process is $201.15 \mathrm{lb} / \mathrm{ton}$ of solid waste burned. Therefore, the residue from RDF on-site burning would be $(309.58 \mathrm{tpd} \times 201.15 \mathrm{lb} /$ ton $) /(2000 \mathrm{lb} /$ ton $)=31.14 \mathrm{tpd}$ which will be disposed of at the landfill.

The electricity generated by burning the RDF on site can be calculated from the following equation:

$$
R_{\text {heat }}(B t u / k W h)=\frac{S_{\text {heat }}(B t u)}{E_{\text {generate }}(k W h)}
$$

where $E_{\text {generate }}$ is the energy generated in a day $(\mathrm{kWh}) . S_{\text {heat }}$ is the heat supplied by the fuel per hour, which can be calculated as: 


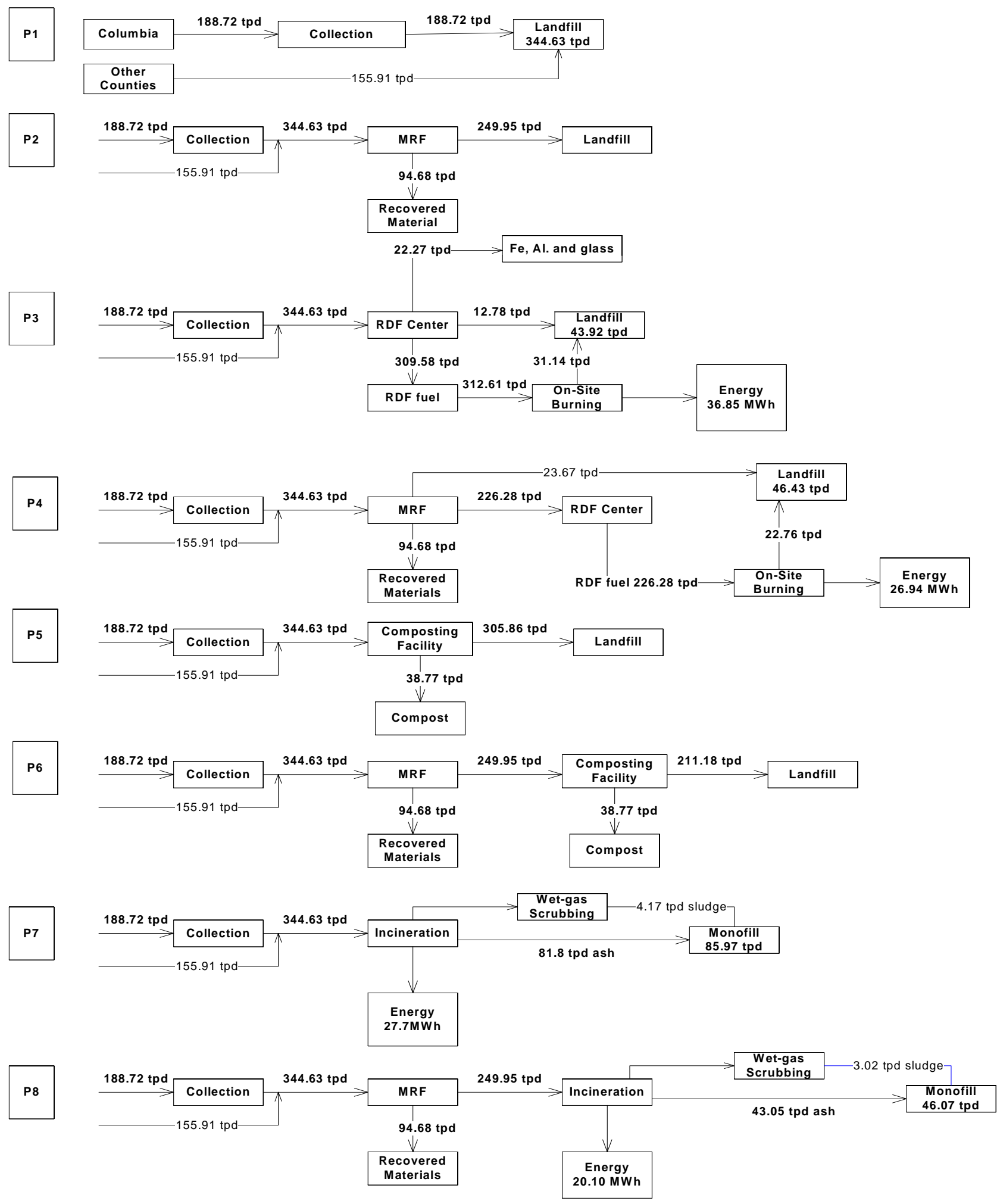

Figure 3. Solid waste management alternatives. 
Table 2. Recyclable Materials Waste Stream Entering the Columbia Landfill

\begin{tabular}{|c|c|c|c|c|}
\hline Commodity & $\begin{array}{c}2004 \text { Price }^{(1)} \\
(\$ / \mathrm{lb})\end{array}$ & $\begin{array}{l}\text { Weight } \\
\text { (tons) }\end{array}$ & $\begin{array}{l}\text { Recovered Weight } \\
\text { (tons) }^{(2)}\end{array}$ & $\begin{array}{c}\text { Market Value } \\
(\$)\end{array}$ \\
\hline \multicolumn{5}{|l|}{ Metal } \\
\hline Aluminum cans $^{(3)}$ & 700 & 634 & 507.2 & $355,040.00$ \\
\hline Other aluminum $^{(3)}$ & 580 & 444 & 355.2 & $206,016.00$ \\
\hline Steel cans & 65 & 2,599 & 2079.2 & $135,148.00$ \\
\hline Ferrous & 65 & 3314 & 2651.2 & $172,328.00$ \\
\hline \multicolumn{5}{|l|}{ Plastic $^{(4)}$} \\
\hline HDPE natural & 460 & 536 & 428.8 & $197,248.00$ \\
\hline HDPE mixed color & 240 & 536 & 428.8 & $102,912.00$ \\
\hline HDPE/PET mixed & 20 & 2,020 & 1616 & $32,320.00$ \\
\hline PET clear loose & 10 & 474 & 379.2 & $3,792.00$ \\
\hline PET mixed color & 10 & 474 & 379.2 & $3,792.00$ \\
\hline \multicolumn{5}{|l|}{ Paper and Paper Board } \\
\hline Newspaper loose & 55 & 5,968 & 4774.4 & $262,592.00$ \\
\hline Corrugated loose & 100 & 15,966 & 12772.8 & $1,277,280.00$ \\
\hline Office mixed loose & 45 & 3,144 & 2515.2 & $113,184.00$ \\
\hline Magazines loose & 100 & 3,922 & 3137.6 & $313,760.00$ \\
\hline \multicolumn{5}{|l|}{ Glass } \\
\hline Clear & 40 & 2,138 & 1710.4 & $68,416.00$ \\
\hline Brown & 30 & 757 & 605.6 & $18,168.00$ \\
\hline Green & 20 & 273 & 218.4 & $4,368.00$ \\
\hline TOTAL & & $43,199.00$ & $34,559.20^{(5)}$ & $3,266,364.00$ \\
\hline Compost (\$/ton) & 2.5 & 28302.74 & 14151.37 & $35,378.42$ \\
\hline \multicolumn{5}{|c|}{$\begin{array}{l}\text { (1) Price obtained from the Associated Recyclers of the Midwest http://recyclingcoop.org/market.htm. } \\
\text { (2) Assumes that } 80 \% \text { of the weight is recoverable. } \\
\text { (3) Annual weight was computed as the mean percentage entering the landfill from this source during Quarters } 3 \text { and } 4 \\
\text { times the total annual weight of all waste entering the landfill from this source, because Quarters } 3 \text { and } 4 \text { were the only } \\
\text { quarters when measurements were taken for aluminum cans. } \\
\text { (4) Arbitrarily assumes the following distribution: PET }(25 \% \text { clear loose, } 25 \% \text { mixed color, } 50 \% \text { mixed with HDPE); } \\
\text { HDPE }(25 \% \text { natural, } 25 \% \text { mixed color, } 50 \% \text { mixed with PET). Assumes that there is no market for the other types of } \\
\text { plastics. } \\
\text { (5) } 34,559.20 \text { ton } / \mathrm{yr}=94.68 \text { tpd. }\end{array}$} \\
\hline
\end{tabular}

$S_{\text {heat }}=\frac{H_{M S W / R D F}(B t u) \times L_{\text {rate }}(t p d)}{24(h / d)}$

where $H_{M S W / R D F}(B t u)$ is the heat value of MSW/RDF, and $L_{\text {rate }}(\mathrm{tpd})$ is the daily loading rate of MSW/RDF (tpd). The parameter $R_{\text {heat }}=$ heat rate $(\mathrm{Btu} / \mathrm{kWh})$ represents the overall conversion efficiency and can be calculated as:

$$
R_{\text {heat }}(B t u / k W h)=\frac{H_{\text {equivalent }}(B t u / k W h)}{\omega_{\text {efficiency }}}
$$

where $H_{\text {equivalent }}$ is the mechanical equivalent of heat and $\omega_{\text {efficiency }}$ is the overall system efficiency.

The values for $H_{\text {equivalent }}$ and $\omega_{\text {efficiency }}$ are 3413 (Btu/kWh) and 0.63 respectively (McGraw-Hill, 1993). The values for $L_{\text {rate }}$ are calculated from mass balance and are equal to 309.58 and 226.28 respectively for Alternative 3 and Alternative 4 . The value for $H_{M S W / R D F}$ is 7738 (Btu) (McDougall, 2001). The electricity generated was then calculated using Equation (11) and determined to be 36.85 (MWh) and 26.94 (MWh) for Alternative 3 and Alternative 4, respectively.

Alternative 4: This alternative is basically Alternative 3 plus recycling (MRF). As calculated in Alternative 2, the total weight of recyclables is 118.35 tpd (Table 2). The recovered materials are $94.68 \mathrm{tpd}$. The residue from the recyclable materials (assuming 20\% recovery) is disposed of at the landfill. The remaining waste that entered an RDF center is 344.63 tpd $-118.35 \mathrm{tpd}=226.28 \mathrm{tpd}$. This waste does not have to go through the metal/glass recycling and oversized item removal 
as in Alternative 3. The waste is processed into RDF fuel and burned on site. The residue from RDF on-site burning would be $(226.28 \mathrm{tpd} \times 201.15 \mathrm{lb} /$ ton $) /(2000 \mathrm{lb} /$ ton $)=22.76 \mathrm{tpd}$ which will be disposed of at the landfill. The energy recovered is calculated using Equation (11).

Alternative 5: This alternative utilizes organic waste composting. There is $1.3 \%$ yard waste and $21.2 \%$ other organic materials in the Columbia Sanitary Landfill waste stream. It is assumed that $50 \%$ of the weight of the original organics is the final compost weight. Thus, the amount of compost produced is $(344.63 \mathrm{tpd} \times 22.5 \%) \times 50 \%=38.77 \mathrm{tpd}$. The remaining waste is $344.63 \mathrm{tpd}-38.77 \mathrm{tpd}=305.86 \mathrm{tpd}$.

Alternative 6: There are 94.68 tpd of recovered materials (see Alternative 2) and 38.77 tpd of compost produced from the yard waste and other organic component of the MSW (see Alternative 5). The residue is $211.18 \mathrm{tpd}$ and is disposed of at the landfill.

Alternative 7: The weights of the waste components are listed in Table 2. The percent of inert residue for each component was obtained from Tchobanoglous et al. (1993). The total residue is $77.63 \mathrm{tpd}$. The alternative assumes that wet-gas scrubbing is used for gas cleaning and that the sludge generated is typically $24.186 \mathrm{lb} /$ ton (McDougall et al., 2001). Therefore, the total sludge generated is $24.186 \mathrm{lb} /$ ton $\times 344.63$ tpd $/ 2000 \mathrm{lb} /$ ton $=4.17 \mathrm{tpd}$. The weight of combustible waste is $344.64 \mathrm{tpd}-77.63 \mathrm{tpd}=267.00 \mathrm{tpd}$, of which $20 \%$ is assumed to be moisture (This percentage was estimated from the data recorded on the cover sheet when the Columbia Sanitary Landfill sorting was performed.). The actual weight of combustibles is 198.07 tpd (or $57.5 \%$ of total waste). The typical heating values for MSW of different percentage of combustibles can be obtained from Tchobanoglous and Kreith, 2002). The heating value for the Columbia waste is estimated as $5227 \mathrm{Btu} / \mathrm{lb}$ based on the percent of combustible content of Columbia waste. The energy recovered $(27.7 \mathrm{MWh})$ is calculated using Equation (11).

Alternative 8: There are $94.68 \mathrm{tpd}$ of recovered materials. The remaining waste is 249.95 tpd and is mass burned. The ash content is estimated in Table 1 and is $43.05 \mathrm{tpd}$. The sludge from the wet-gas scrubbing is $24.19 \mathrm{lb} /$ ton $\times 249.95$ tpd $/ 2000 \mathrm{lb} /$ ton $=3.02 \mathrm{tpd}$.

\subsection{Definition of Evaluation Criteria}

Each criterion represents the interest of one or more of the stakeholders or members of the taskforce. Criteria can be determined through a similar process as that outlined above for determining the alternatives. The set of criteria $(U)$ that was defined for the Columbia case study are as follows. The criteria that are within the economic category are Capital Cost (\$) (u1), Operation and Maintenance Cost (\$/day) (u2) and Revenue (\$/day) (u3), which is the income from recovered recyclables. The criteria within the environmental category are Energy Recovered (MWh) (u4) and Air Emissions (kg/day) (u5), which are pollutant emissions to air such as acid gases, carbon dioxide, and particulate matter. The criteria within the social category are Diversion Rate $(u 6)$, which is the percentage of the waste that would not enter landfill; the Public Acceptance $(u 7)$, which reflects how the public accepts the solution based on their feelings regarding such considerations as the odor, traffic impact, noise, and benefits (e.g., cheaper electricity); and Employment (u8), which was defined in the study as the number of new skilled and unskilled jobs created. The set was established by the authors to demonstrate the methodology and the tool.

\section{Criterion 1: Capital Cost (u1)}

Criterion 1 is the total capital cost of the system. The capital costs found in the literature vary. The factors that affect the capital cost are the facility location, regulatory requirements that must be met, local waste stream characteristics, etc. Typical unit capital costs for various solid waste management options are listed in Tchobanoglous and Kreith (2002). The values used in this study are $\$ 100,000 /$ truck for waste collection, $\$ 10,000 /$ ton of waste per day for an MRF facility, $\$ 10,000 /$ ton of waste per day for composting, $\$ 20,000$ for an RDF-production facility, $\$ 80,000 /$ ton of waste per day for incineration, $\$ 25,000 /$ ton of waste per day for landfilling, and $\$ 10,000 /$ ton of waste per day for monofilling. The total capital cost for a waste management alternative can be calculated as follows:

$u 1=Z_{\text {collection }} N_{\text {truck }}+\sum_{i} Z_{i} B_{\text {daily }}$

where $u 1=$ total capital cost for an alternative; $Z_{\text {collection }}=$ capital cost for waste collection (\$/truck); $N_{\text {truck }}=$ number of trucks needed for collection; $Z_{i}=$ capital cost for waste treatment facility $i$ to treat one ton of waste per day ( $\$ /$ ton/day); and $B_{\text {daily }}=$ amount of waste that a facility handles per day (ton/day).

Representative capital costs were calculated for the 8 alternatives based on Equation (14) and are shown in Table 3. The number of trucks required for collecting the waste from the City of Columbia is 24 (City of Columbia Solid Waste Division, 2004). Because the waste collected from the city of Columbia was 188.72 ton/day, the average weight of waste per truck is 8 ton/truck.

\section{Criteria 2: Operation and Maintenance Cost $(u 2)$}

Like the capital costs, operation and maintenance (O\&M) costs exhibit large variations in literature case studies due to local differences in labor rates, safety rules, crew sizes, age of the facilities, etc. The O\&M cost can be calculated as follows:

$u 2=\sum_{i}\left(Z_{O \& M}\right)_{i} B_{d a i l y}$

where $\left(Z_{O \& M}\right)_{i}$ is the O\&M unit cost for treatment facility $i$ and $B_{\text {daily }}=$ amount of waste that a facility handles per day (ton/day). Literature O\&M unit costs for major solid waste management options can be found in Tchobanoglous and Kreith (2002). The values for different options are $\$ 60 /$ ton for waste collection, \$20/ton for an MRF facility, \$20/ton for a 
Table 3. Criteria Values for the 8 Alternatives

\begin{tabular}{lcccccccc}
\hline \multicolumn{1}{c}{ Criteria } & $P 1$ & $P 2$ & $P 3$ & $P 4$ & $P 5$ & $P 6$ & $P 7$ & $P 8$ \\
\hline$u$ 1 (million \$) & 11.02 & 12.10 & 10.36 & 11.53 & 13.49 & 13.63 & 30.83 & 26.30 \\
u2 (thousand \$/day) & 14.77 & 20.72 & 18.64 & 23.21 & 21.27 & 25.33 & 25.97 & 28.67 \\
u3 (\$/day) & 0.00 & $89,48.94$ & $2,628.72$ & $8,948.94$ & 96.93 & $9,045.87$ & 0.00 & $8,948.94$ \\
$u 4(\mathrm{MWh})$ & 0.00 & 0.00 & 36.85 & 26.93 & 0.00 & 0.00 & 27.71 & 20.10 \\
u5 (kg/day) & 0.00 & 0.00 & 839.50 & 654.91 & 0.00 & 0.00 & 840.18 & 839.50 \\
$u 6(\%$, ton/ton) & 0.00 & 27.47 & 87.26 & 86.53 & 11.25 & 38.72 & 76.26 & 86.63 \\
$u 7$ (rating 0-10 scale) & 6.50 & 7.33 & 6.67 & 7.25 & 7.00 & 7.25 & 5.33 & 6.50 \\
$u 8$ (number of persons) & 80.00 & 109.00 & 86.00 & 115.00 & 83.00 & 112.00 & 81.00 & 110.00 \\
\hline
\end{tabular}

composting facility, $\$ 20 /$ ton for an RDF production facility, $\$ 40 /$ ton for incineration, and $\$ 10 /$ ton for a landfill or a monofill. The O\&M costs per day for the 8 alternatives were calculated based on Equation (15) and are shown in Table 3.

\section{Criteria 3: Revenue (u3)}

The magnitude of revenues depends on what components are recovered and the amount of each waste recovered component. It also depends on the availability of a market for the recovered products. The revenue is calculated as

$u 3=($ Unit Price of Recovered Materials $)$

$\times$ (Amount of Recovered Materials)

The recyclable components and their 2004 market values are shown in Table 2. It was assumed that the recovery rate of the waste is $80 \%$. The total revenues for the 8 different alternatives are calculated based on Equation (16) and are shown in Table 3.

\section{Criteria 4: Energy Recovered (u4)}

Energy can be recovered from burning MSW or RDF. Because some of the non-combustible components are removed during the process of producing RDF, it is usually more efficient to burn RDF than raw MSW. In addition, RDF can be stored or sold, while MSW has to be burned on site. The calculation of energy recovery was discussed in the mass balance section. The results are shown in Table 3.

\section{Criterion 5: Air Emissions (u5)}

Because there are different kinds of emissions from different processes, it is necessary to define which emissions will be considered. A list of important emissions needs to be identified by stakeholders, particularly the technical professionals. In this study, the implicit environmental burdens due to electricity consumption, the use of fuels, etc., and the pollutants discharged to water are not considered. The air pollutants $\mathrm{SO}_{2}, \mathrm{HCL}, \mathrm{NO}_{\mathrm{x}}$ (as $\mathrm{NO}$ ), dioxins/furans, $\mathrm{CO}$, and particulate matter (PM) were considered in this study. These air pollutants are regulated by the USEPA. The emission factors (kg/ton) for the above air pollutants were calculated by McDougall (2001) by multiplying the USEPA regulatory limit by the estimated volume of flue gas generated per ton of the waste combusted. The emissions factors were multiplied by the waste component weights (ton/year) in Table 4 to obtain emissions (kg/day) for each component. For Alternative 3, the "After RDF Recycling" column in Table 4 was used. For Alternative 8, the "After MRF Recycling" column was used. The emissions for each component were added up to obtain the total emissions for an alternative (Table 3 ).

For composting, the major air emission will be carbon dioxide, which contributes to the greenhouse effect. Odor problems can occur in aerobic composting processes due to the development of anaerobic conditions within the compost pile. For simplicity, these are not considered in the calculations for this study.

\section{Criterion 6: Diversion Rate (u6)}

The diversion goal is defined as the percentage of the waste that will not enter a landfill. USEPA has set a national goal of $40 \%$ by 2010 (USEPA, 1996). In order to achieve this goal, local communities have set up their own diversion goals for different time periods. Some communities have gone beyond USEPA's goal. The diversion goal can be calculated as follows:

$u 6=1-\frac{N_{\text {wast }}}{W_{\text {wast }}}$

where $u 6=$ diversion rate; $N_{\text {waste }}=$ amount of waste entering landfill per year; and $W_{\text {waste }}=$ total amount of waste generated. The diversion rates for the 8 alternatives are calculated based on Equation (17) and are shown in Table 3.

\section{Criterion 7: Public Acceptance (u7)}

Information about the public acceptance of solid waste management options can be obtained by conducting public meetings and working with focus groups to present details about the alternative waste management plans and to collect feedback. The public can rate the alternatives based on how they feel about the potential odor, traffic impact, noise, and benefits such as cheaper electricity for the community. The public acceptance can be calculated as follows:

$u 7=\sum R_{\text {rating }} \frac{N_{R}}{N_{\text {surveye }}}$ 
Table 4. Waste Component Weight after RDF Partial Recycling and MRF Recycling

\begin{tabular}{lccc}
\hline $\begin{array}{c}\text { Waste } \\
\text { Components }\end{array}$ & $\begin{array}{c}1996 \text { Weight } \\
\text { (ton) }\end{array}$ & $\begin{array}{c}\text { After MRF Recycling } \\
\text { (ton) }\end{array}$ & $\begin{array}{c}\text { After RDF Recycling } \\
\text { (ton) }\end{array}$ \\
\hline Paper & 24952 & 1752 & 24952 \\
Glass & 3612 & 1078 & $1078^{(2)}$ \\
Ferrous metal & 3314 & 663 & $663^{(2)}$ \\
Other metal $^{(3)}$ & 4272 & 1330 & $1330^{(2)}$ \\
Film plastic $^{(4)}$ & 5631 & 5631 & 5631 \\
Rigid plastic $^{(5)}$ & 14194 & 10962 & 14194 \\
Textiles $^{(6)}$ & 4788 & 4788 & 4788 \\
Organics $^{(6)}$ & 21817 & 21817 & 21817 \\
Other $^{(7)}$ & 43209 & 43209 & 43209 \\
Total $_{\text {Ton per day }}^{125789}$ & 91230 & 117662 \\
\hline
\end{tabular}

\footnotetext{
${ }^{(1)}$ Waste components were re-grouped to match the components listed in McDougall (2001)'s emission factors.

${ }^{(2)}$ Ferrous, and aluminum and steel cans and glass are recycled for RDF.

(3) Other metal includes non-ferrous, alum and steel can (which was recycled).

(4) Film plastic was assumed to be LDPE.

${ }^{(5)}$ Rigid plastics are all plastics other than LDPE.

${ }^{(6)}$ Organics are assumed to be wood, food waste, manure and other organics.

${ }^{(7)}$ Other includes all of the paperboards and other waste.
}

where $R_{\text {rating }}=$ rating that people give to an alternative (on a scale of 0 to 10 , where $0-1$ corresponds to strongly disapprove; 2-3 corresponds to somewhat disapprove; 4-6 corresponds to neutral; 7-8 corresponds to somewhat approve; and 9-10 corresponds to strongly approve); $N_{R}=$ number of people who give the rating R; $N_{\text {survey }}=$ total number of people surveyed.

The rating for each component of an alternative can be obtained and an average of all the component ratings can be used as the final rating for that alternative. The researcher selected arbitrary values for acceptance for each alternative and the average was used to demonstrate the methodology; the results for the 8 alternatives are shown in Table 3.

\section{Criterion 8: Employment (u8)}

Employment is defined as the number of new skilled and unskilled jobs created. The employment data for an MRF can be found in Tchobanoglous and Kreith (2002). The employment requirement for a 300 tpd MRF is 32 total employees including 2 maintenance employees, 3 forklift/loader operators, 26 sorters, and 1 foreman/operator. This was estimated by taking the average of values for 100 tpd and 500 tpd facilities. There are no employment data available in the literature for the other options. For an RDF, the employment opportunities created are estimated from the values for a 300 tpd MRF by subtracting the number of sorters (26) from the total number of employees (32). The employment for incineration is estimated in the same way. The employment for other options were obtained from City of Columbia information and are 70 for collection, 29 for an MRF, 3 for a composting facility, and 10 for landfills. The overall results are shown in Table 3.

\subsection{Define Stakeholders (S)}

Possible stakeholders are local elected officials, community/neighborhood groups, citizens, regulatory agencies, municipal employee, (landfill operators, waste collection system representatives), and representatives from the recycling industry, the resource recovery industry and environmental groups. The stakeholder groups considered for this demonstration are defined as follows. $S=\{s 1, s 2, s 3, s 4, s 5\}$, where $s 1=$ City Council; $s 2=$ General Public; $s 3=$ Non-Governmental Organizations; $s 4=$ Government Employees; and $s 5=$ Technical Professionals.

The stakeholders would rate each criteria on a 0-10 scale, where 9-10 corresponds to extremely important, 7-8 corresponds to somewhat important, 4-6 corresponds to neutral, 2-3 corresponds to somewhat unimportant, and 0-1 corresponds to extremely unimportant. The results for this case study, where the authors provided the rating, were then aggregated using the "fuzzy and" operator according to Equation (5). An arbitrary value of 0.5 for $\lambda$ was assumed for this study. The selection of the $\lambda$ value is open for future research. The aggregated importance values are then normalized to show relative difference. The values are depicted in Figure 4.

\section{Results and Discussion}

Based on calculations in section 4 , the criteria values for the 8 alternatives are shown in Table 3. The membership function for each criterion was arbitrarily chosen as follows: an exponential membership function was chosen for $u 1-u 5$ (Equation 8), while a linear membership function was chosen 
for $u 6-u 8$ (Equation 7).

Equation (10) was used to perform the fuzzy composition, and results are depicted in Figure 5. As one can see from Figure 5, based on the values utilized for this case study, Alternative 4 would be the best alternative for managing the waste stream entering the City of Columbia Landfill.

As discussed in section 2, the most commonly used aggregation operators are logical AND and OR (corresponding to min and max) operators and averaging operators (Equation (3), Equation (4), Equation (5), and Equation (6)). A comparison of the results using different aggregation operators is shown in Figure 4. One can see that the results for this case study are not very sensitive to the usage of different aggregation operators.

In order to assess how the fuzzy importance factors of the criteria affect the results, hypothetical extreme fuzzy weighting factors were assigned to the three categories of criteria. Three scenarios are tested and defined as follows:

Scenario 1: The Economic Point of View. In this scenario, the economic criteria are considered "extremely important" and assigned fuzzy membership values of 10. Environmental and social criteria are considered "extremely unimportant" and assigned fuzzy membership values of 0 . The results of the final fuzzy ranking are shown in Figure 6.

Scenario 2: Environmental Point of View. In this scenario, the environmental criteria are considered "extremely important" and assigned fuzzy membership values of 10 . Social and economic criteria are considered "extremely unimportant" and assigned fuzzy membership values of 0 . The results of this fuzzy ranking are shown in Figure 7. Although Alternative 4 and Alternative 8 involve incineration, they ranked fairly high because energy recovery was also considered as an environmental factor.

Scenario 3: Social Point of View. In this scenario, the social criteria are considered "extremely important" and assigned fuzzy membership values of 10. Economic and environmental criteria are considered "extremely unimportant" and assigned fuzzy membership values of 0 . The results of this fuzzy ranking are shown in Figure 8.

As can be seen from Figures 6 through 8, the results change with the three alternative points of view defined in the three testing scenarios. These results indicate that different perspectives on the importance of different criteria result in different alternatives being considered optimal.

As discussed in section 2.3, there are different fuzzy composition operators. Three commonly used operators (max-min, max-product, and sum-product) are discussed in section 2.3 and are compared in this section. The fuzzy ranking results from using the three composition operators are shown in Figures 9 through 11. The fuzzy composition values were normalized so that they are in the same scale and can be compared. As can be seen from the figures, the sum-product composition allows for the differentiation of preferences between solid waste management options and hence performs better than the other two composition operators considered, in the context of solid waste management planning.

\section{Conclusions}

A fuzzy multi-criteria decision-support model was developed. It solves the problem of imprecision and fuzziness involved in the solid waste decision-making process. It takes into consideration multiple evaluation criteria and multiple stakeholders. The methodology and tool were demonstrated using Columbia, Missouri solid waste information, incurporating general inputs where Columbia-specific information was not available, and utilizing author-specified preferences. The test case results are significant in confirming the operational nature of the tool and the ability of the methodology to translate differences in preferences into differentiated optimal options. This model and operational tool will be useful for informing stakeholders regarding solid waste management, and for assisting local officials and technical professionals in making planning for integrated solid waste management more transparent and justifiable.

\section{References}

Anex, R.P., Lawver, R.A., Lund, J.R. and Tchobanoglous, G. (1996). GIGO: Spreadsheet-based simulation for MSW Systems. J. Environ. Eng., 122(4), 259-262.

Chang, N.B. and Lin, Y.T. (1997). An analysis of recycling impacts on solid waste generation by time series intervention modeling. Resour., Conserv. Recycling, 19, 165-186.

Chang, N.B., Yang, Y.C. and Wang, S.F. (1996). Solid-waste management system analysis with noise control and traffic congestion limitations. J. Environ. Eng., 122(2), 122-131.

City of Columbia's Solid Waste Utility (1996). Oral conversation with Columbia's solid waste utility. http:// www.gocolumbiamo.com/PublicWorks/Solidwaste/.

Everett, J.W. and Shahi, S. (1996). Curbside collection of yard waste: I. Estimating route time. J. Environ. Eng., 122(2), 107-114.

Fodor, J. and Roubens, M. (1994). Fuzzy Preference Modeling and Multicriteria Decision Support, Kluwer Academic Publishers, Boston.

Haith, D.A. (1998). Materials balance for municipal solid waste management. J. Environ. Eng., 124(1), 67-75.

Kaila, J. (1987). Mathematical Model for Strategy Evaluation of Municipal Solid Waste Management System, Technical Research Center of Finland, Publications 40, ESPOO 1987.

Klir, G.J. and Yuan, B. (1995). Fuzzy Sets and Fuzzy Logic Theory and Applications, Prentice Hall PTR, Upper Saddle River, New Jersey.

Klir, G.J. and Yuan, B. (1996). Fuzzy Sets, Fuzzy Ligic, and Fuzzy Systems, Selected Papers by L.A. Zadeh, World Scientific. New Jersey.

Lowen, R. (1996). Fuzzy Set Theory: Basic Concepts, Techniques and Bibliography, Kluwer Academic Publishers, Boston.

Lund, J.R. (1990). Least-cost scheduling of solid waste recycling. $J$. Environ. Eng., 116(1), 182-197.

Lund, J.R., Tchobanoglous, G., Anex, R.P. and Lawver, R.A. 1994). Linear programming for analysis of material recovery facilities. J. Environ. Eng., 120(5), 1082-1094.

McDougall, Forbes, Peter White, Marina Franke and Peter Hindle. (2001). Integrated Solid Waste Management, A life cycle inventory, Blackwell Science, UK.

Pugh, M.P. (1993). The use of mathematical models in evaluating 

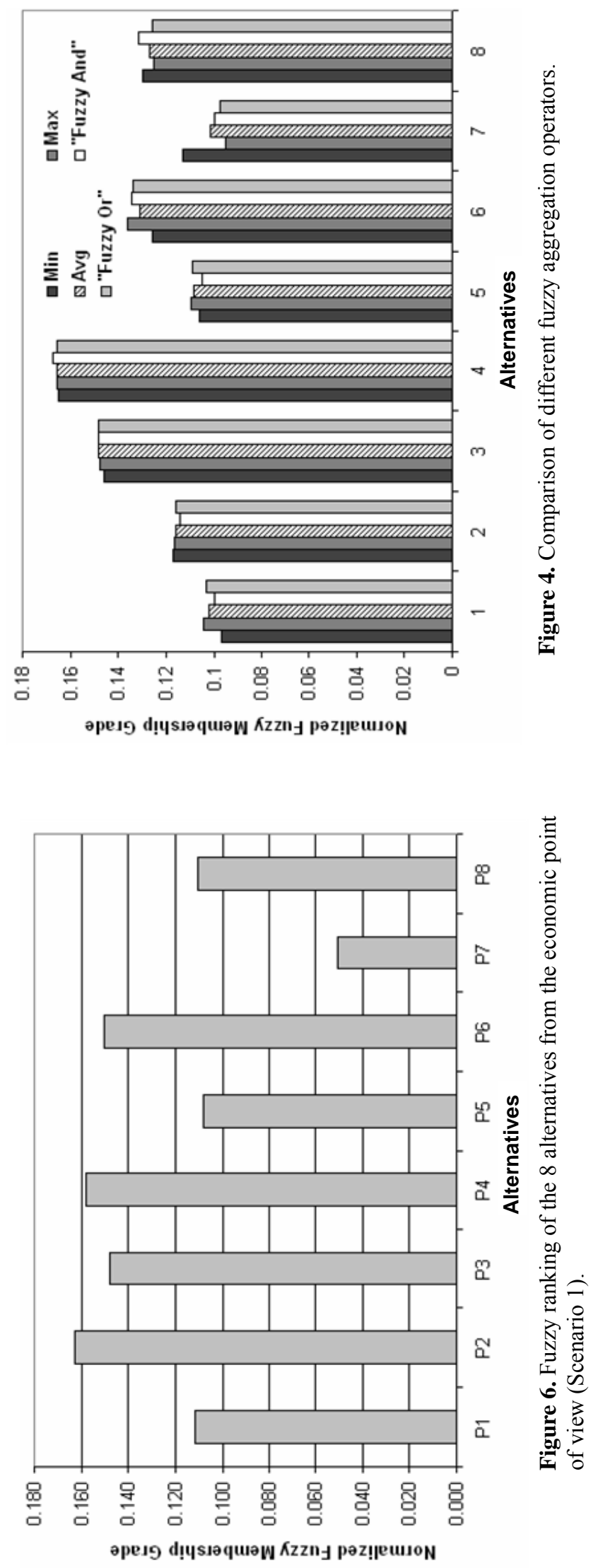
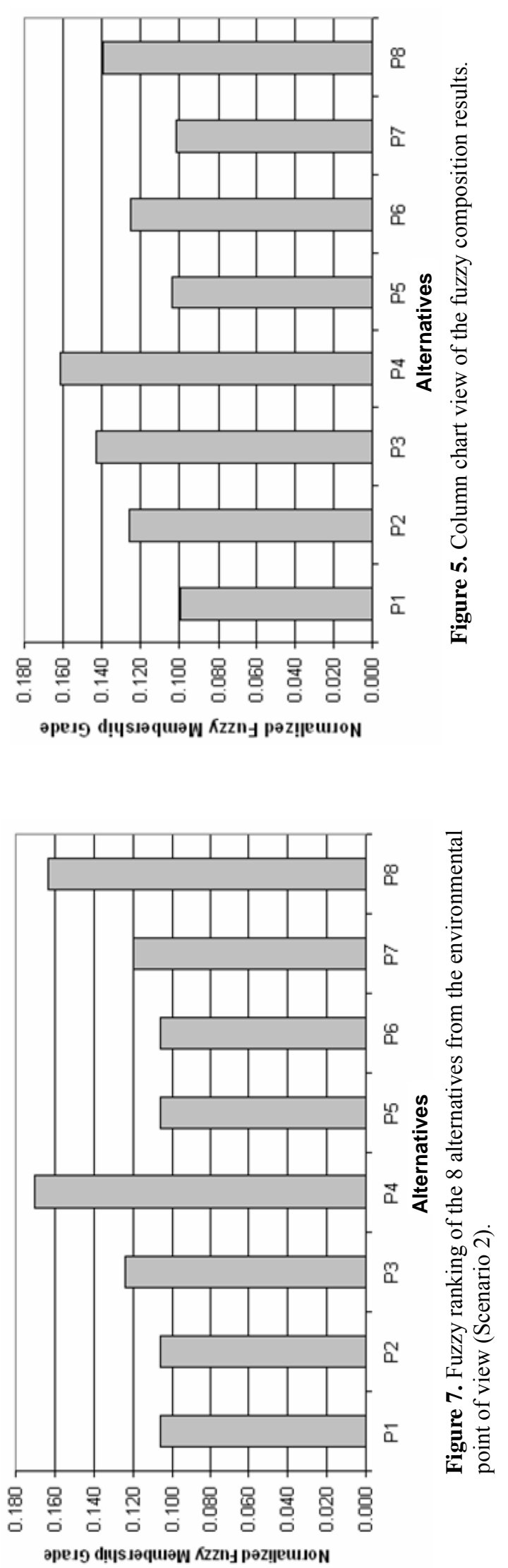

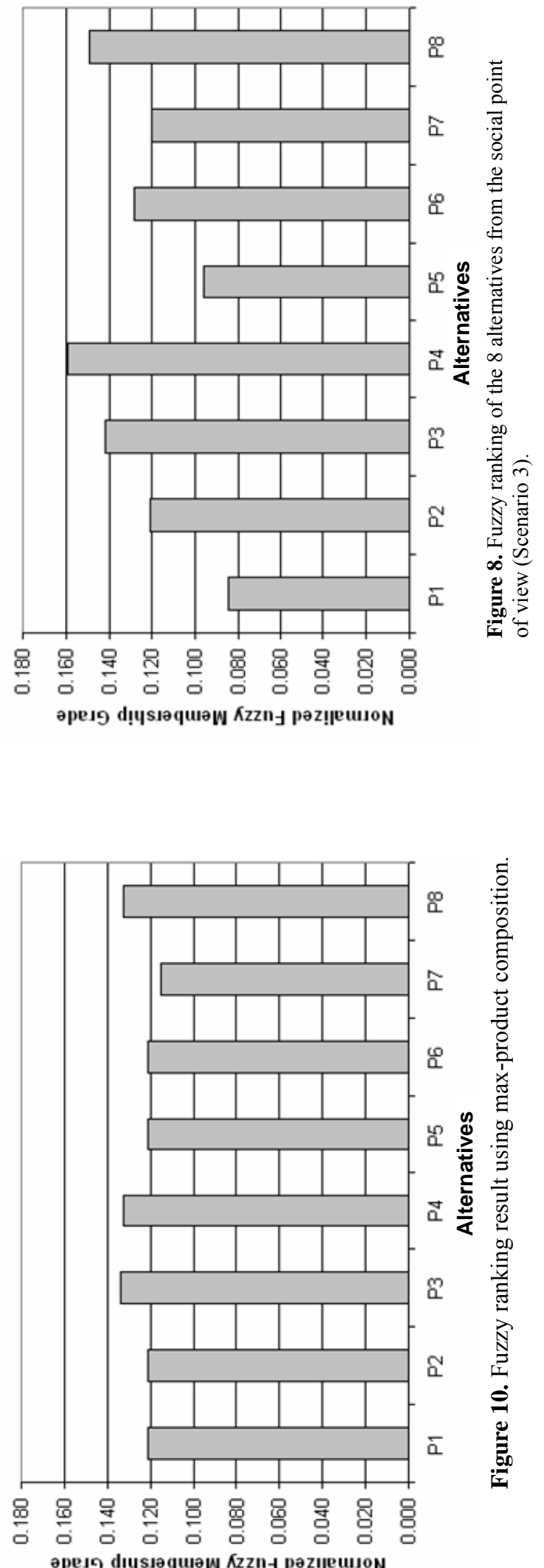
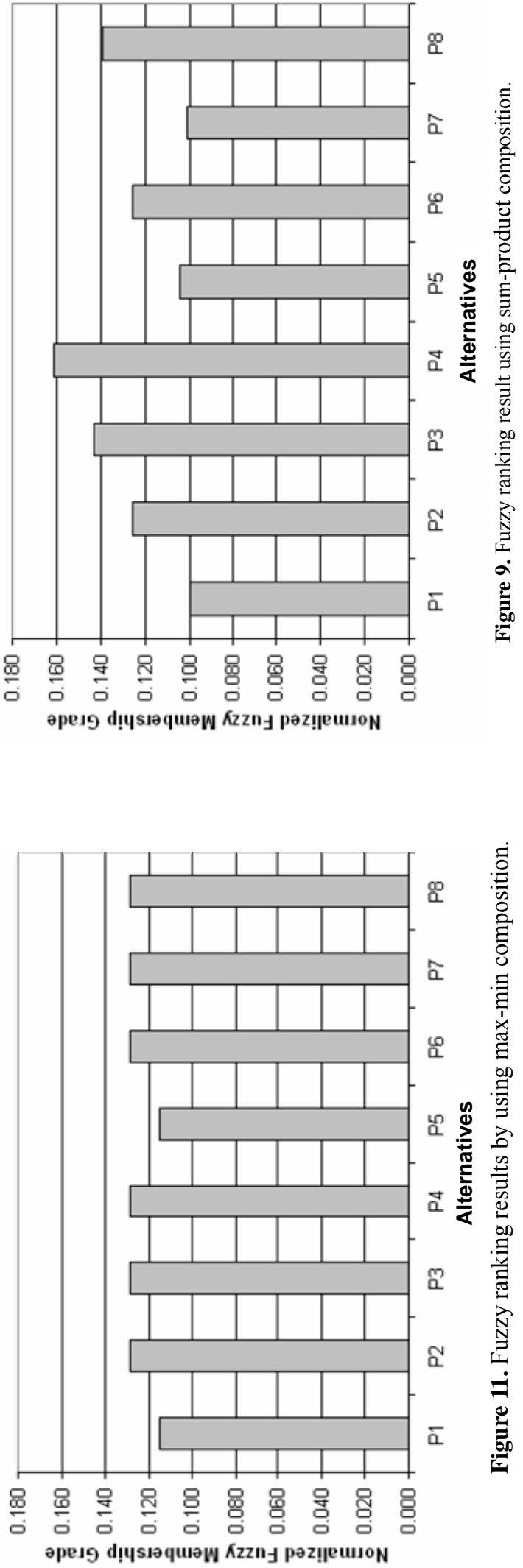
resource recovery options. Resour., Conserv. Recycling, 8, 91-101.

Tchobanoglous, G., Theisen, H. and Vigil, S. (1993). Integrated Solid Waste Management, Engineering Principles and Management Issues, Irwin McGraw-Hill, Boston.

US Environmental Protection Agency (1996). Characterization of Municipal Solid Waste in the United States: 1995 Update, EPA 530-R-96-001, PB96-152 160, US Environmental Protection Agency, Office of Solid Waste, Washington, DC.

US Environmental Protection Agency (2005). What is the solid waste management hierarchy.

http://www.epa.gov/garbage/faq.htm\#1 (last visited on July 8, 2005).
Wang, L.X. (1997). A Course in Fuzzy Systems and Control, Prentice Hall PTR, Upper Saddle River, New Jersey.

Zadeh, L.A. (1965). Fuzzy sets. Inform. Control, 8, 338-353.

Zeng, Y. (2004). Internet-Based Fuzzy Logic and Statistics Models for Integrated Solid Waste Management Planning, Ph.D. Dissertation, University of Missouri-Columbia.

Zeng, Y., Trauth, K.M., Peyton, R.L. and Banerji, S.K. (2005). Characterization of solid waste disposed at Columbia Sanitary Landfill in Missouri, Waste Manage. Res., 22, 1-10.

Zimmermann, H.J. (1996). Fuzzy Set Theory and Its Applications Third Edition, Kluwer Academic Publishers, London. 